\title{
Research on the Effective Strategies for College Students' Party Building to Enter the Internet
}

\author{
Haitao $\mathrm{Li}^{1 \text {,a }}$ \\ ${ }^{1}$ College of Information and Control Engineering, Jilin Institute of Chemical Technology, Jilin City, Jilin Province, \\ 132022, China \\ a466137114@qq.com
}

Keywords: College students' Party building; Network; Effective strategies; Necessity

Abstract. With the rapid development of the information age, the scientific construction of the Party building that enters the network is required, so that the college students' Party building work can gradually open up the new connotation and space. The speed of network communication is fast, so the new field of vision can be expanded and the new information on the network platform can be obtained in time. The Party building work of the universities should not only carry out the basic line of the Party, but also make the contemporary college students have enough knowledge of the Party's great cause, so as to promote the further development of college students' Party building work. Therefore, colleges and universities should make an in-depth analysis from the aspect of the opportunities and challenges of college students' Party building work that enters the network, and put forward effective solutions.

\section{大学生党建工作进网络的有效对策研究}

摘要：信息时代的迅速发展，要求党建工作进网络的科学建设，使大学生党建工作逐渐开拓了新的内涵和空间。网络传 播的速度开的特点，从而扩大新的视野，在网络平台能够及时获得新资讯，各大高校的党建工作不仅要贯彻党的基本路线更 应该使当代大学生对于党的伟大事业有足够的认知，从而促进了大学生党建工作的深入发展。因此，高校应从大学生党建工 作进网络的机遇与挑战等方面进行深入的分析，并提出有效的解决对策。

关键词：大学生党建；网络；有效对策；必要性

\section{1 大学生党建工作进网络的必要性}

大学生党建工作是党的战斗力和基础。各大高校大学生党建工作党建工作的基础。加强大学生党建工 作基本内涵的理解, 进一步实现大学生党建工作的目标。着重加强教育事业与党的建设工作, 将其作为党 建工作的重要部分。大学生党建工作是党为在高校选拔人才而建立的一个工作体系, 其意义在于培养学生 党员。大学生党建的工作客体可以分为三方面: 入党积极分子、学生党员和党组织, 工作主体是党建工作 者。实现以网络作为高速载体，发挥网络思想政治教育的教育功效，促进社会和谐健康发展的基本需求。

\section{1 大学生党建进网络建设是现代信息技术政策的体现}

党中央一直高度重视和发展网络信息化建设的基本方针“积极发展, 加强管理, 趋利避害, 为我所用”, 因此我国在全球信息网络化的世界中争取取得领先地位，把大学生的党建工作引入网络，将网络的优势发 挥最大的作用。习近平指出： “网络信息是跨国界流动的，信息流引领技术流、资金流、人才流，信息资 源日益成为重要生产要素和社会财富, 信息掌握的多塞成为国家软实力和竞争力的重要标志。信息技术和 产业发展程度决定着信息化发展水平，要加强核心技术自主创新和基础设施建设，提升信息采集、处理、 
传播、利用、安全能力, 更好惠及民生。” 1因此全球信息网络化过程中包含了社会、政治、经济、文化 和生活的各个方面, 大学生党建工作也发现了新的机遇、挑战。党中央面对这些机遇与挑战应不断地探索 解决。进一步推进大学生党建工作进网络, 实现党建工作的新篇章。

\section{2 大学生党建进网络建设与大学生流动党员现状同步}

改革开放后, 我国的经济结构逐渐加强, 人口流动基数增大, 各类组织如雨后春笋般迅速发展。大学 生党员队伍的职业构成也发生了翻天覆地的变化, 在某些方面加强了对毕业大学生党员的管理, 大学的党 员职位存在差别, 但其针对党的建设性规律的内涵是不变的。大学生党员就应当为普通群众做个榜样, 将 自己培养成最佳成员, 进一步推进大学生党建工作的发展。我国开创大学生网络党建的目的便是为了统筹 兼顾, 通过网络手段不断提高大学生党员的素养, 从而可以使其能在所学领域发挥实质性的作用。

\section{3 大学生的特点决定加强大学生党建工作进网络}

网络发展迅速崛起, 导致大学生特点思维方式开阔, 价值观更加的多元化, 但政治尚有不成熟, 使在 面临网络迅速发展时的影响及與论导向不能的判断正确的方向, 及时的做出正确的决定。但当代大学生是 国家的动力源泉, 更是未来国家发展的重要力量。因此高速发展的信息化网络世界, 需要积极网络文化的 对当代大学生的重陶和渲染, 使他们的政治想法逐渐成熟, 树立正确的政治观念、坚定的信念。现代化党 建的是需要党员的组织结构足够团结, 足够坚硬。但由于全国的党员年龄结构的比例差距明显加大, 不利 于影响党建的科学性合理发展。因此为党建事业的发展以及大学生成长的必经道路, 必须充分发挥网络资 源, 进一步提高大学生党建工作的发展。

\section{2 网络时代大学生党建工作面临的机遇和挑战}

网络使大学生党建工作更为便捷。大学生党建工作将网络合理利用会使工作的效率明显提高。传统的 学生党建工作以开板报、开报告会等方式为主。现如今网络迅速发展畅通, 党建工作以网络在传播的方式, 使党建工作传播更迅速, 更广泛, 更加有针对性。可以让党建工作者及时了解党员动态, 调节矛盾。网络 的发展是大学生党建开拓出新的目标及方向。网络提供了交流的平台, 使人们忽略外界因素, 在此平台人 们可以, 畅所欲言。网络集音频、文本、图画于一体, 生动而巧妙地将党建工作在网上展现在学生眼前, 使学生党建更具影响力。但是, 网络是一把 “双刃剑”, 惠及国人的同时, 也方便了西方文化的渗透, 使国 内思想受到冲击, 从而导致使一部分学生缺乏入党的积极性。此外, 由于接受教育的水平不同, 导致大学 生的文化素质各不相同, 思想道德与价值观念等复杂纷繁, 给大学生党建工作造成了一定的障碍。主要表 现在以下三个方面: 第一、有一部分学生党员意志不坚定, 过于功利化。网络的开放性使国外文化得以向 渗透, 而西方国家便凭借他们在网络上的优势, 对大学生的思想造成了冲击, 对学生成长十分不利。因网 络不良信息的影响, 导致一部分学生党员理念动摇, 学习政治理论的热情下降, 社会责任感降低, 甚至产 生了类似于个人主义的不良思想, 与大学生党建背道而驰。第二、党员数量激增, 但各大高校的党建组织 机构以及队伍并不能很好的掌握运用网络发展的特点。因此导致高校经过多年招生后, 学员人数却相对缺 之, 由此产生了两大问题: 一方面学校政工干部没有足够的精力进行党建工作; 另一方面一些党建工作者 虽然有许多实践经验, 却难以适应网络党建的新要求。有一部分政工工作者难以抓住时事热点, 无法为受

1 习近平. 主持召开中央网络安全和信息化领导小组第一次会议并发表重要讲话[R/OL]. (2014-2-27) [2014-11-20] http://internal.dbw.cn/system/2014/11/20/056143113.shtml. 
教育者提供具有说服力的信息。于是, 培养一批既懂得思想政治教育又具有过硬的网络技术的新型学生党 建工作者便势在必行。第三、大学生党建需求明显增高, 高校基层的现状相对于落后。因此高校应加强自 我分析, 从而找寻问题, 比如: 对发展大学生党员缺乏认识; 对学生党员的教育工作不够重视; 对学生党 员队伍中发生的问题不能及时有效的解决; 有一部分基层党建组织教育形式单一, 过于注重思想理论方面 的教育而忽视了实践的作用, 导致一些学生党员只懂理论却不会把理论应用到现实当中去; 提高高校就业 率是高校最想加以解决的问题, 因此就会出现党员数量明显增多, 但大学生党员的质量却出现问题, 严重 违背了党员发展方针。第四, 大部分高校党建工作科技含量偏低, 难以充分利用网络和科技增强学生党建 工作的生命力。

\section{3 大学生党建工作进网络的对策}

\section{1 处理好三种关系协调党建工作}

交互性与保密性的关系。党内保密是大学生党建工作中的基本准则, 互联网的开放性使大学生党建工 作必须做好保密措施。但在其保密地基础上党部成员可以更好的相互进行交流与学习、工作汇总, 学生同 样可以通过网络平台行使自己的监督权, 实时向党反应情况, 但有一些党建内容是属于保密范畴的, 所以 应当注意防护工作。网络就像是一把 “双刃剑”, 一方面通过网络人们可以便捷工作, 另一方面也对我们 的隐私造成了一定的危险性。大学生党建网络在进程中, 正向功能扩大, 开拓了大学生党建的新航路, 使 大学生党建工作进一步完善。但党建内容的保密性是至关重要的。因此, 针对应用网络党建交互性服务的 同时, 我们做好引导工作, 能够正确识别用户的意图, 及时做出反应, 保证网站的健康安全运行。网络党 建模式与传统党建模式的关系。建立以传统党建模为基础的思想观, 是对传统党建的一种延伸; 是传统党 建工作的一个深度拓展。党建工作网络化有效的缩短了信息传播的空间距离, 我们要充分利用这种优势填 补传统党建模式的不足。全面规划与重点建设的关系。网络党建的载体有很多。因此在面对这些多种多样 的网络载体, 高校各级党组织应认真研究当中的规律, 结合以往的成功经验, 全面推进网络党建进程。在 重点筹划那些较为成熟的网络载体的同时, 应坚持以党建网络载体的统筹规划利用为前提。当今, 有些高 校开展网上党校工作, 通过网络视频讲座进行远程教学, 有效地推进了对入党积极分子、学生党员、基层 党工作者的教育和培训, 其成功经验值得我们借鉴。

\section{2 培养好三支队伍占领网络思想阵地}

高速发展的信息化世界里, 高校想要建立一个网络思想教育基地, 那么建立一只工作经验丰富、政治 素养过硬的队伍是不可缺少的。因此, 应加大对党建相应队伍的建设, 持续促进大学生党建工作向更深层 次的发展。其次, 网络党建的专职干部队伍应当优先考虑专职党务工作者和政治辅导员, 因为他们是与学 生接触最频繁且最具基层工作经验的干部队伍。这只队伍是大学生网络党建工作的关键所在。为此, 高校 需要完善相应的激励机制, 对党建工作者的选拔更要抓住党建网络化水平这一硬性要求。在选任辅导员时, 应结合计算机能力和网络运用水平严加考核。学生的思想政治教育也是网络党建的重中之重。政治导师在 课堂授课、网络交流和学生的思想引导上有着不可替代的作用。高校的网络教育水平必须加强, 只有把教 育和网路相结合, 才会使高校大学生党建发挥到更加完美。大学生党员应将把自己提高到最好状态, 充分 发挥他们在网络党建过程中的积极作用。从而实现党员自我教育、自我管理、自我服务的目的。

高校应积极培养网络党建工作队伍, 定期举办相关讲座和培训为党建工作者们打造一个交流的平台, 
提高他们的网络党建水平和解决实际问题的能力, 打造一个高素质、高能力的网络党建队伍。于此同时, 学校要积极开展党员志愿者服务活动, 加强学生的实践能力, 为学校党建水平的提高做贡献。

\section{3 积极创建学生党建网络平台拓展网络思想阵地}

网络思想政治教育主阵地需要及时创建，因为在网络信息时代迅速发展的情况下，网络环境的健康影 响着大学生党建工作者的思想, 一些非马克思主义思想意识不择手段地通过网络渗透, 妄图以青年一代为 突破口, 实现我国西化的阴谋。所以建立党的数据信息库的工作便势在必行, 只有这样才能在网上斗争中 占据主动权。大学生党建网络作为网络思想政治教育的利器, 牵动着网络教育的走向。因此, 高校需要对 网络思想阵地的扩建采取正确得措施。努力把学生党建网站建设成一个凝聚大学生的 “红色阵地”, 并且 引导当代大学生建立的思想政治马克思主义和社会主义价值观, 以保证党的思想意识在网络上开拓出新的 阵地。

积极在网络领域中发展大学生党建工作的宣传, 加强大学生的思想教育其中包括马列主义、毛泽东思 想、邓小平理论和三个代表的重要思想、习近平 “四个全面” 战略思想，从而树立正确的思想方向。通过 党建网络选出新时期共产党员的先进典范, 以榜样的力量加深党的影响力, 促使学生奋进。宣传应以多手 段、多形式、创意新颖为前提，可以考虑将网上宣传和在线文字交流相结合，以相关讲座、电影以及论文 来加强广大学生对党的认识, 将党建深入到人们的生活当中。充分利用学生党建网络的快捷性、交互性等 特点, 实现网上思想汇报、网上申请入党等工作。

\section{参考文献:}

［1］隋海娇．关于加强和改进高校大学生党建工作的几点思考 [J]．赤子(上中旬).2017 (02)

[2] 刘礼俊. 大学生党建工作对辅导员素质和能力的要求 [J]. 当代教育实践与教学研究. 2017(08)

[3] 廖勇，夏泉．社区育人视角下的大学生党建工作探析 $[J]$ ．暨南学报(哲学社会科学版)．2017 (08)

[4] 孙剑秋. 高校大学生党建与学风建设共建机制研究 [J]．中国多媒体与网络教学学报 (电子版)。2017 (04)

[5] 毛文娟. 新形势下高职院校大学生党建工作存在问题与对策研究 $[J]$. 南京工业职业技术学院学报. 2016 (04)

[6] 卢琳，马维红．建立大学生党建与就业工作的共赢模式 [J]。黑龙江科学. 2016 (01)

[7] 彭义雯．新形势下大学生党建工作的创新开展 $[J]$ ．文学教育(下)．2016 (07)

[8］杨敏，陈燕．善用新媒体做好大学生党建工作 $[J]$ ．新闻战线．2014(12)

[9] 陈孟增．新常态下大学生党建工作实践与探索 $[J]$. 党史文苑. 2015(16)

[10］胡风琴. 基于实践观的大学生党建平台建设探析 [J]. 教育教学论坛. 2015(41)

\section{References}

[1] H.J.Sui: Reflections on Strengthening and Improving College Students' Party Building Work[J], Chi Zi(the first and middle ten days of a month), 2017(02).(In Chinese)

[2] L.J.Li: Requirements of College Students' Party Building on the Quality and Ability of Counselors[J], Contemporary Education Research and Teaching, 2017(08).(In Chinese)

[3] Y.Liao and Q.Xia: Exploring the Party Construction Oriented for University Students from the Perspective of Community Education[J], Jinan Journal(Philosophy and Social Sciences), 2017(08).(In Chinese)

[4] J.Q.Sun: Research on Co-construction Mechanism of Party Building and the Construction of Study Style of College Students[J], China Journal of Multimedia \& Network Teaching(Electronic Edition), 2017(04).(In Chinese)

[5] W.J.Mao: Problem and Countermeasure Research on Party Construction for College Students under the New Situation[J], Journal of Nanjing Institute of Industry Technology, 2016(04).(In Chinese)

[6] L.Lu and W.H.Ma: The Establishment of a Win-Win Model of College Students' Party Construction and Employment[J], Heilongjiang Science, 2016(01).(In Chinese) 
[7] Y.W.Peng: Innovative Development of College Students' Party building under the New Situation, [J], Education Literature(Lower). 2016(07).(In Chinese)

[8] M.Yang and Y.Chen: The College Students' Party Building Work Can be Well Done by Making Good Use of New Media[J], News Front, 2014(12).(In Chinese)

[9] M.Z.Chen: Practice and Exploration of College Students' Party Construction under the New Normal[J], Literary Circles of Cpc History, 2015(16).(In Chinese)

[10] F.Q.Hu: Exploration of the Construction of College Students' Party Building Platform Based on Practice View[J], Education Teaching Forum, 2015(41).(In Chinese) 